CLINICAL STUDY

\title{
Immigration and the incidence of Graves' thyrotoxicosis, thyrotoxic multinodular goiter and solitary toxic adenoma
}

\author{
Mikael Lantz ${ }^{1}$, Mirna Abraham-Nordling ${ }^{3,4}$, Johan Svensson ${ }^{2}$, Göran Wallin ${ }^{3}$ and Bengt Hallengren ${ }^{1}$ \\ Departments of ${ }^{1}$ Endocrinology and ${ }^{2}$ Pediatrics, Malmö University Hospital, 20502 Malmö, Sweden, ${ }^{3}$ Department of Surgery, Karolinska Hospital and \\ Institute, Stockholm 17176, Sweden and ${ }^{4}$ Division of Surgery, Department of Clinical Sciences, Karolinska Institutet, Danderyd Hospital, Stockholm \\ 18288 , Sweden \\ (Correspondence should be addressed to M Lantz; Email: mikael.lantz@med.lu.se)
}

\begin{abstract}
Objective: Environmental and genetic factors influence thyrotoxicosis, but how population migration affects the disease panorama is not known. In an urban area in southern Sweden, during the years 1990 until 2003, the population increased from 232000 to 267000 . In parallel, the proportion of inhabitants born outside Sweden increased.

The aim was to investigate whether the incidence of Graves' thyrotoxicosis (GD), toxic multinodular goiter (TMNG), and solitary toxic adenoma (STA) has changed in Malmö since 1990 and to study the influence of geographic origin.

Design and method: An open label prospective registration of thyrotoxicosis, gender, age, smoking habits, and ethnic background during 2003-2005 in an urban area in southern Sweden (Malmö) was undertaken.

Results: The total incidence of thyrotoxicosis has changed from 43 to 41.6 cases/100 000/year from the years 1988-1990 to 2003-2005 ( $p$-value 0.72). GD increased from 22 to 29.6 ( $p$-value 0.0051), TMNG decreased from 16 to 9.9 ( $p$-value 0.0011) and STA from 4.8 to 2.1 ( $p$-value 0.0054)/100 000/year. The total incidence of GD was higher in inhabitants born outside Sweden up to the age of 69 years and age-specific incidence showed a peak in women aged 50-59 years old in both groups. The greatest difference between immigrants and Swedes up to the age of 69 years was observed in women aged 20-29 years old.

Conclusion: The incidence of GD has increased and of TMNG has decreased in Malmö since 1990. Geographic origin seems to affect the incidence of GD. Whether the observed peak in age-related incidence in women 50-59 years is explained by menopausal changes has to be further investigated.
\end{abstract}

European Journal of Endocrinology 160 201-206

\section{Introduction}

The incidence of thyrotoxicosis has previously been determined in Sweden and studies showed a variation between 25.8 and 43.0 cases per 100000 per year (1-4). In other studies in Europe, outside Sweden, performed in Iceland, Denmark, and the UK the incidence varied between 9.7 and 56.5 per 100000 and year (5-10). In a study in New Zealand, the incidence was 25.8 per 100000 per year (11). Factors such as type of area studied, time period, type of method, and types of thyrotoxicosis included may explain some of the variations. In addition, the inclusion of children or not may also affect the total incidence.

However, it is well known that genetic, environmental, and endogenous factors influence development of thyrotoxic disease and factors like gender, age, smoking habits, family history, stress, and iodine status contribute to the type of thyroid illness (12-14).

In an urban area (Malmö) in southern Sweden the incidence of thyrotoxicosis as well as Graves' disease increased between the time periods1970-1974 and 1988-1990 (3). Several factors like more sensitive diagnostic tools and smoking habits were suggested as explanations. Since 1990, until 2003, the population in Malmö increased from 232000 to 267000 , concomitantly the proportion of inhabitants born outside Sweden increased more than the proportion of inhabitants born in Sweden. The aim in this prospective study was to further investigate if factors like geographic origin affect the incidence of thyrotoxicosis.

\section{Material and methods}

\section{Patients}

The study was approved by the ethical review board, Lund University, Malmö/Lund, Sweden, and informed consent was obtained before inclusion. All patients living in the town of Malmö, without a previous history of thyrotoxicosis, and newly diagnosed with overt 
thyrotoxicosis due to Graves' disease (GD), thyrotoxic multinodular goiter (TMNG), or solitary toxic adenoma (STA) during the years 1 January 2003-31 December 2005 were prospectively registered and included. Patients with thyroiditis or recurrence of thyrotoxicosis were not included. The diagnosis of thyrotoxicosis was based on clinical symptoms and signs, plasma concentrations of TSH $<0.2 \mathrm{mIU} / \mathrm{l}$, increased plasma levels of free $\mathrm{T}_{4}$ and/or free tri-iodothyronine $\left(\mathrm{T}_{3}\right)$. The area of inclusion was Malmö, a seaport town in southern Sweden, with a mean population of 269195 inhabitants during the time period 2003-2005. There is only one hospital in Malmö, the population is demographically well defined and the town is suitable for epidemiological studies. From the years 1990 to 2003, the population increased from 232000 to 267000 and the proportion of inhabitants born outside Sweden increased from $16 \%$ in 1990 to $25 \%$ in 2003 . Demographic information of the population in Malmö was obtained from the database Official Statistics of Sweden. The following parameters were registered at diagnosis of thyrotoxicosis: age, gender, type of thyrotoxicosis (GD, TMNG, and STA), smoking habits (smokers, ex-smokers, and non-smokers), and geographic background (born in Sweden, born in Europe outside Sweden, and born outside Europe). The patients were classified as having GD on the basis of clinical signs, presence of TSH receptor antibodies (TRab), and/or a diffuse uptake on technetium scintigraphy. The diagnosis of TMNG and STA was based on clinical signs, the uptake on technetium scintigraphy and the absence of TRab. The majority of patients were included at their first visit to the department of Endocrinology. Patients were also included at the departments of Pediatrics or Oncology at Malmö University Hospital or after visiting a private practitioner. All general practitioners in Malmö received a letter where they were asked to inform us if they treated patients with thyrotoxicosis. We also checked registers of diagnosis at departments of Endocrinology, Pediatrics, Oncology, Surgery, and Internal Medicine at Malmö University hospital. Lund University hospital is situated close to Malmö and we also checked their diagnosis registers for the presence of patients with a home address in Malmö. We find the previous study 1988-1990 valid and comparable because the structure of the hospital and the uptake area were similar. In addition, one of the authors $(\mathrm{B} \mathrm{H})$ of this study was a co-author of the previous study.

\section{Assays}

Using the ELISA technique, plasma TSH (reference interval $0.4-3.5 \mathrm{mIU} / \mathrm{l}$, sensitivity $0.001 \mathrm{mIU} / \mathrm{l}, \mathrm{CV}$ $10 \%$ ), free $\mathrm{T}_{4}$ (reference interval $8-14 \mathrm{pmol} / \mathrm{l}$, sensitivity $2 \mathrm{pmol} / \mathrm{l}, \mathrm{CV} 10 \%$ ), free $\mathrm{T}_{3}$ (reference interval 3.5$5.4 \mathrm{pmol} / \mathrm{l}$, sensitivity $2 \mathrm{pmol} / \mathrm{l}, \mathrm{CV} 10 \%$ ) were measured according to the manufacturers description
(Beckman Coulter, Bromme, Sweden) in clinical routine at department of Clinical Chemistry at Malmö University hospital.

TRab was measured in a routine laboratory using a human radio receptor assay kit purchased from Brahms and following the instructions from the supplier (reference interval <1 IU/l, sensitivity $0.3 \mathrm{IU} / \mathrm{l}, \mathrm{CV}$ 9.3-15.4\%). For information of the assays used in the previous study, please see Berglund et al. (3).

\section{Statistical analysis}

Episheet, written by Ken Rothman (http://members.aol. com/krothman/modepi.htm), was used to calculate incidence differences with 95\% confidence interval, and to test incidence differences and homogeneity (15).

\section{Results}

The incidence of thyrotoxicosis in Malmö has previously been registered retrospectively in the years 1988-1990. In this study, patients with thyrotoxicosis were prospectively registered during the years 2003-2005. The incidence of Graves' thyrotoxicosis (GD) increased by $33 \%$ as compared to the years 1988-1990 (Table 1). This was in contrast to the incidence of TMNG and STA which decreased by 38 and 56\% respectively (Table 1 ). The total incidence was slightly changed, 41.6 in 20032005 vs 43.0 in 1988-1990.

In GD, the age-specific incidence 2003-2005 showed a significantly changed distribution as compared with 1988-1990 with a distinct maximum in the age-group 50-59 years (confidence interval -29.9 to -0.5 ; Fig. 1A). In the group with TMNG or STA the agespecific incidence was generally on a significantly lower level during the years 2003-2005 as compared with 1988-1990 except in patients older than 80 years (Fig. 1B). The sex ratio of females and males in GD was 3.8 to 1 (Table 1 ) which is similar to $1988-1990$ but in

Table 1 Incidence of Graves thyrotoxicosis (GD), toxic multinodular goiter (TMNG), and solitary toxic adenoma (STA) per 100 000/year in Malmö during the time periods 2003-2005 and 1988-1990 and ratio of females and males.

\begin{tabular}{lllll}
\hline & Total & GD & TMNG & STA \\
\hline Mean incidence & $41.6(336)$ & $29.6(239)$ & $9.9(80)$ & $2.1(17)$ \\
2003-2005 $(n)$ & & & & \\
Female $(n)$ & 273 & 189 & 69 & 15 \\
Male $(n)$ & 63 & 50 & 11 & 2 \\
Ratio & $4.3: 1$ & $3.8: 1$ & $6.3: 1$ & $7.5: 1$ \\
Mean incidence & $43.0(299)$ & $22.3(155)$ & $16.0(111)$ & $4.8(33)$ \\
1988-1990 $(n)$ & & 126 & 105 & 32 \\
Female $(n)$ & 263 & 29 & 6 & 1 \\
Male $(n)$ & 36 & $4.3: 1$ & $18: 1$ & $32: 1$ \\
Ratio & $7.3: 1$ & 0.0051 & 0.0011 & 0.0054 \\
$P$ value & 0.72 & & & \\
\hline
\end{tabular}

*Number of individuals. 

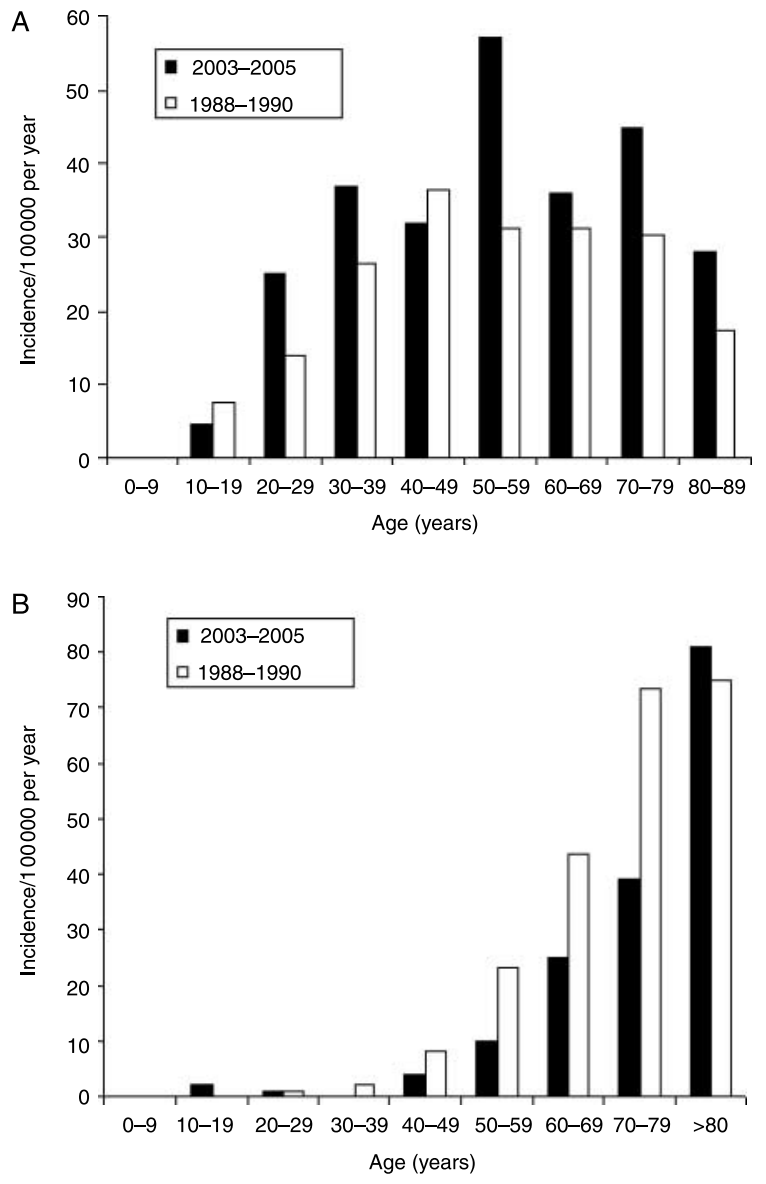

Figure 1 (A) Age-specific incidence of Graves' thyrotoxicosis and (B) toxic multinodular goiter or solitary toxic adenoma in Malmö during the years 1988-1990 (white bars) and 2003-2005 (black bars). The homogeneity $P$ value was 0.0048 for Graves thyrotoxicosis (A) and for toxic multinodular goiter/solitary toxic adenoma was $<0.001$ when comparing rates of incidences for the two periods of time.

patients with TMNG and STA the proportion of males was increased (Table 1). There was an over-representation of smokers in GD as compared with TMNG and STA (Table 2).

Between the years 1988-1990 and 2003-2005 the population in Malmö increased by $15 \%$ and the inhabitants born outside Sweden increased by $54 \%$. During the same time period, the incidence of GD increased and the proportion of GD in immigrants was increased as compared with patients born in Sweden (Table 3). In the group with TMNG and STA, the proportion of patients born outside Sweden was decreased as compared with patients born in Sweden (Table 3). This was not explained by a shift in the ratio women/men because the proportion was similar in immigrants and Swedes, but the age-structure shows that the proportion of inhabitants older than 70 years was increased in the latter group (Table 4). How about smoking habits in immigrants and Swedes? The highest
Table 2 The proportion (\%) and number $(n)$ of smokers, ex-smokers and non-smokers in Graves' thyrotoxicosis (GD), toxic multinodular goiter (TMNG) and solitary toxic adenoma (STA) in Malmö in the years 2003-2005.

\begin{tabular}{llll}
\hline & Total & GD & TMNG + STA \\
\hline $\begin{array}{llll}\text { Smokers }(n) \\
\quad \text { Female \% }\end{array}$ & $27.7(70)$ & $31.1(56)$ & $19.4(14)$ \\
$\begin{array}{l}\text { Male \% } \\
\text { Ex-smokers }(n)\end{array}$ & $21.1(12)$ & $17.8(8)$ & $33.3(4)$ \\
$\quad \begin{array}{l}\text { Female \% } \\
\text { Male \% }\end{array}$ & $26.5(67)$ & $25.0(45)$ & $30.6(22)$ \\
$\begin{array}{l}\text { Non-smokers }(n) \\
\quad \text { Female \% }\end{array}$ & $50.9(29)$ & $51.1(23)$ & $50.0(6)$ \\
$\quad$ Male \% & $45.8(115)$ & $43.9(79)$ & $50(36)$ \\
$\begin{array}{l}\text { Unknown smoking } \\
\text { habits }(n)\end{array}$ & $28.1(16)$ & $31.1(14)$ & $16.7(2)$ \\
$\quad$ Female \% & & & \\
Male \% & $7.6(21)$ & $4.8(9)$ & $14(12)$ \\
\hline
\end{tabular}

proportion of smokers was seen in patients born in Europe, outside Sweden, and the lowest proportion was seen in patients born outside Europe, which also showed the highest share of GD, therefore factors other than smoking may contribute to GD.

Age-specific incidence in women with Graves' was higher in patients born outside Sweden than in females born in Sweden in all age-groups up to 69 years but statistically not significantly different (Fig. 2). The highest incidence was seen in the age-group 50-59 years both in women born in and outside Sweden which was statistically significant as compared with the age-

Table 3 Geographic background, (A) type of thyrotoxicosis, (B) sex and $(C)$ smoking habits in patients with thyrotoxicosis in Malmö during the years 2003-2005.

\begin{tabular}{|c|c|c|c|}
\hline A. & $\begin{array}{l}\text { Graves' } \\
\text { disease }\end{array}$ & $\begin{array}{l}\text { Toxic } \\
\text { multinodular } \\
\text { goiter }\end{array}$ & $\begin{array}{l}\text { Solitary } \\
\text { toxic } \\
\text { adenoma }\end{array}$ \\
\hline Born in Sweden \% $(n)$ & $66.5(157)$ & $27.5(65)$ & $5.9(14)$ \\
\hline $\begin{array}{l}\text { Born in Europe out- } \\
\text { side Sweden \% }(n)\end{array}$ & $82.5(47)$ & $14.0(8)$ & $3.5(2)$ \\
\hline $\begin{array}{l}\text { Born outside Europe } \\
\%(n)\end{array}$ & $85.0(34)$ & $12.5(5)$ & $2.5(1)$ \\
\hline Total $^{\mathrm{a}}$ & $71.5(238)$ & $23.4(78)$ & $5.1(17)$ \\
\hline \multicolumn{2}{|l|}{$B$. } & Female & Male \\
\hline \multirow{4}{*}{\multicolumn{2}{|c|}{$\begin{array}{l}\text { Born in Sweden } \%(n) \\
\text { Born in Europe outside Sweden \% }(n) \\
\text { Born outside Europe \% }(n) \\
\text { Total }{ }^{\mathrm{b}}\end{array}$}} & $82.3(195)$ & $17.7(42)$ \\
\hline & & 1) 78.9 (45) & 21.1 (12) \\
\hline & & 77.5 (31) & $22.5(9)$ \\
\hline & & $81.1(271)$ & $18.9(63)$ \\
\hline C. & Smokers Ex & Ex-smokers & Non-smokers \\
\hline$\%(n)$ & $24.8(53) \quad 32$ & $32.7(70)$ & $42.5(91)$ \\
\hline $\begin{array}{l}\text { Born in Europe out- } \\
\text { side Sweden \% }(n)\end{array}$ & $42.1(24) \quad 33$ & $33.3(19)$ & $24.6(14)$ \\
\hline $\begin{array}{l}\text { Born outside Europe } \\
\%(n)\end{array}$ & $10.5(4)$ & $18.4(7)$ & $71.1(27)$ \\
\hline Total $^{\mathrm{C}}$ & $26.2(81) \quad 31$ & $31.1(96)$ & $42.7(132)$ \\
\hline
\end{tabular}

${ }^{\mathrm{a}}$ Missing data in three patients.

${ }^{\mathrm{b}}$ Missing data in two patients.

${ }^{\mathrm{c}}$ Missing data in 27 patients. 
Table 4 Age-structure of the population in Malmö born in or outside Sweden during the years 2003-2005.

\begin{tabular}{lcc}
\hline Age group (years) & $\begin{array}{c}\text { Born in Sweden } \\
(\%)^{\mathrm{a}}\end{array}$ & $\begin{array}{c}\text { Born outside } \\
\text { Sweden }(\%)^{\mathrm{a}}\end{array}$ \\
\hline $0-9$ & 12.9 & 2.80 \\
$10-19$ & 11.7 & 9.20 \\
$20-29$ & 15.7 & 18.6 \\
$30-39$ & 13.8 & 16.3 \\
$40-49$ & 10.7 & 18.6 \\
$50-59$ & 11.2 & 14.0 \\
$60-69$ & 9.10 & 11.0 \\
$70-79$ & 7.90 & 5.80 \\
$80-89$ & 5.80 & 2.30 \\
$90-99$ & 1.10 & 0.30 \\
\hline
\end{tabular}

${ }^{\text {a }}$ Proportion of the total number of inhabitants in the group.

group 40-49 years ( $p$-value 0.022, confidence interval 5.6-71.8; Fig. 2). The greatest difference in age-specific incidence between the two groups was seen in the agegroups 20-29 and 70-79 years, but was found not significant (Fig. 2).

\section{Discussion}

The present report describes a change in the incidence of GD and TMNG where the proportion of GD has increased and TMNG has decreased in Malmö during the time periods 1988-1990 until 2003-2005. In parallel, the share of immigrants in Malmö has increased more than the population in general and it is shown that the proportion of GD is higher and TMNG/STA is lower in the immigrant group. The age-specific incidence is the highest in the age-group 50-59 years.

Stress is one factor with impact on the development of GD (14). Therefore, one explanation could be that immigrants in general, may find it stressful to live in a new country. However, one would expect an overrepresentation of patients who have lived in Sweden for

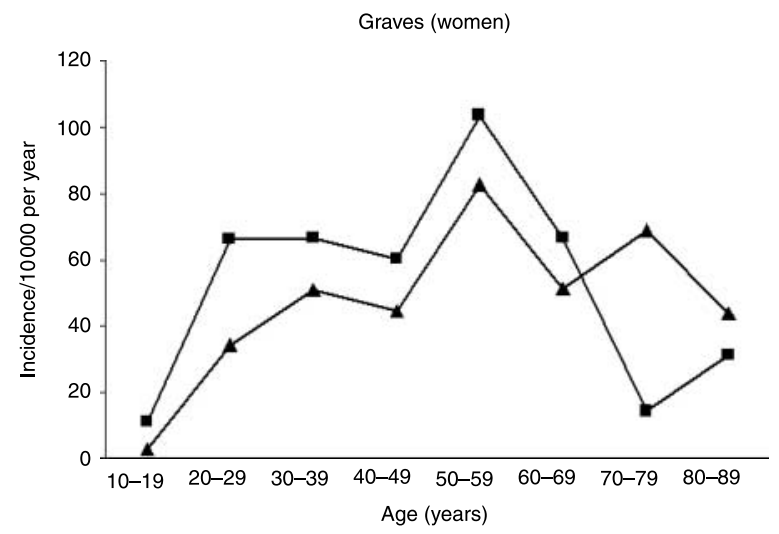

Figure 2 Age-specific incidence of Graves' thyrotoxicosis in females born in Sweden (triangles) or outside Sweden (squares). The homogeneity $P$ value was 0.12 when comparing rates of incidences in the two groups. a short period of time but there was no simple correlation to the time lived in Sweden (data not shown).

Another factor that can affect the development of GD is a change in iodine status especially if the iodine intake is sharply increased, but a chronic iodine excess has been suggested not to increase the incidence of GD $(16,17)$. A high incidence of GD has previously been demonstrated in the young in an area with high iodine intake and it has also been shown that when increasing the iodization of salt, hyperthyroidism increased in young subjects where GD is expected to predominate $(12,18)$. In our study, we do not have data on the actual iodine status, but Sweden is assumed to be iodine sufficient because the salt has been iodized since 1936, with an increase of added iodine from 1966 . We do not have knowledge of the actual iodine status in the population of immigrants but a substantial proportion of the immigrants may come from areas with iodine deficiency. This can be one factor that may contribute to the high share of GD found in the group of patients born outside Europe.

Genetic factors have been shown to strongly influence the development of autoimmune thyroid disease in twins but the impact of specific genes is still poorly understood (19). The most consistently found genes are HLA class II, CTLA4, PTPN22 and Thyrotropin receptor. Other genes where strong evidence is building are TG, CD4O, IL2RA, and FCRL3 (20). It is thought that the genotype of GD is polygenic and that different mixes of genes will affect the risk to develop the phenotype of Graves. One of the most consistently found genes in autoimmune thyroid disease was CTLA4 that has been found in both Caucasian and Asian subjects (21). In our study, we do not yet have information on the genetic background of patients born in Sweden or in immigrants. Whether the difference in incidence between these groups is explained by an influx of new gene variants or a different mixture of risk genes has to be investigated in future studies.

Smoking is suggested to be a major risk factor in Graves' ophthalmopathy and a minor risk factor in GD $(22,23)$. The latter fact is supported by our data because the proportion of smokers varied between the groups with different geographic origin where the lowest share of smokers was observed in the group with the highest share of GD. Therefore, factors other than smoking may contribute to GD.

Estrogen has been shown to be lower in smoking women and the use of oral contraceptives or estrogen has been associated with a lower frequency of GD (24-27).

Another observation in the present study was the large difference in age-related incidence in women 2029 years born in Sweden or outside Sweden where the latter group exhibited a significantly higher incidence. It is well known that the postpartum period is associated with an increased frequency of GD that may influence 
the described difference in incidence if immigrant women had their children at a younger age as compared with Swedish women (28). In this study, we have analyzed the age-related incidence and found the highest incidence of GD in women 50 - 59 years old, an age when the majority of women are supposed to have achieved menopause. Whether the observed peak of incidence is explained by lowered levels of estrogen or a changed use of estrogen in the postmenopausal period has to be further investigated. Recently, a polymorphism in the estrogen receptor $\beta$-gene has been shown to be associated with a susceptibility to GD, however, functional studies have not been performed to test if decreased estrogen receptor responses increase the risk to develop GD (29). In other types of autoimmune diseases like rheumatoid arthritis a significantly higher radiographic joint destruction has been shown in postmenopausal patients than in premenopausal patients (30). Whether estrogen replacement therapy protects against rheumatoid arthritis has been under debate and the impact of estrogen replacement therapy in autoimmune thyroid disease should be further studied (31).

How about the decrease in TMNG and STA. Since 1990, the assay for TRab has become more sensitive and as a result several of the earlier TMNG/STA patients may have been re-classified as GD. Today, it is also more common to treat subclinical hyperthyroidism that preferentially may have reduced the cases with overt TMNG. In addition, the long tradition of using iodized salt may now have full effect on the reduction of nodular goiter in the Swedish population, that was observed in an incidence study of the Swedish inland (2). In the immigrant group, we preferentially found GD and only a small share of TMNG that may also affect the total number of cases especially since the immigrant group has increased more than the Swedish group. In addition, the proportion of inhabitants above 70 years old is reduced in immigrants who may in part explain the low number of cases with TMNG/STA in this group.

To conclude, the incidence of GD has increased and of TMNG/STA has decreased in Malmö since 1990, and the incidence was affected by several factors like geographic origin, age, and smoking habits. Whether the observed peak in age-related incidence of GD in women 50-59 years old is explained by menopausal changes has to be further investigated.

\section{Declaration of interest}

The authors declare that there is no conflict of interest that could be perceived as prejudicing the impartiality of the research reported.

\section{Funding}

This work was supported by grants from research funds from Malmö University Hospital, the Faculty of Medicine at Lund University, Skåne Research Foundation and the Albert Påhlsson Foundation.

\section{Acknowledgements}

The authors wish to thank colleagues at the departments of Endocrinology, Surgery, Oncology, Pediatrics, and Internal Medicine at Malmö University hospital for their support in the inclusion of study patients. We also wish to express our sincere gratitude to associate Professor Per Katzman, head of the department of Endocrinology at Lund University Hospital for allowing us to check their diagnosis registers. We are also grateful to Helene Jacobsson, RSKC Lund, for help with calculation of statistics.

\section{References}

1 Berglund J, Borup Christensen S \& Hallengren B. Total and agespecific incidence of Graves' thyrotoxicosis, toxic nodular goitre and solitary toxic adenoma in Malmö 1970-1974. Journal of Internal Medicine 1990227 137-141.

2 Lundgren E \& Borup Christensen S. Decreasing incidence of thyrotoxicosis in an endemic goitre inland area of Sweden. Clinical Endocrinology 199033 133-138.

3 Berglund J, Ericsson U-B \& Hallengren B. Increased incidence of thyrotoxicosis in Malmö during the years 1988-1990 as compared to the years 1970-1974. Journal of Internal Medicine $199623957-62$.

4 Abraham-Nordling $\mathrm{M}$, Törring $\mathrm{O}$, Lantz $\mathrm{M}$, Hallengren $\mathrm{B}$, Ohrling H, Lundell G, Calissendorff J, Jörneskog G \& Wallin G. Incidence of hyperthyroidism in Stockholm, Sweden, 2003-2005. European Journal of Endocrinology 2008158 823-827.

5 Mogensen EF \& Green A. The epidemiology of thyrotoxicosis in Denmark. Acta Medica Scandinavica 1980208 183-186.

6 Barker DJP \& Philips DIW. Current incidence of thyrotoxicosis and past prevalence of goitre in 12 British towns. Lancet 19842 567-570.

7 Haraldson A, Gudmundsson ST, Larusson G \& Sigurdsson G. Thyrotoxicosis in Iceland 1980-1982. Acta Medica Scandinavica $1985217253-258$.

8 Vanderpump MP, Tunbridge WM, French JM, Appleton D, Bates D, Clark F, Grimley-Evans J, Hasan DM, Rodgers H, Tunbridge F \& Young ET. The incidence of thyroid disorders in the community: a twenty-year follow-up of the Wickham survey. Clinical Endocrinology 199543 55-68.

9 Laurberg P, Bulow Pedersen I, Pedersen KM \& Vestergaard H. Low incidence rate of overt hypothyroidism compared with hyperthyroidism in an area with moderately low iodine intake. Thyroid 1999 $933-38$.

10 Leese GP, Flynn RV, Jung RT, Macdonald TM, Murphy MJ \& Morris AD. Increasing prevalence and incidence of thyroid disease in Tayside, Scotland: the thyroid epidemiology audit and research study (TEARS). Clinical Endocrinology 200868 311-316.

11 Brownlie BE \& Wells JE. The epidemiology of thyrotoxicosis in New Zealand: incidence and geographical distribution in north Canterbury, 1983-1985. Clinical Endocrinology 199033 249-259.

12 Laurberg P, Pedersen KM, Vestergaard H \& Sigurdsson G. High incidence of multinodular toxic goitre in the elderly population in a low iodine intake area versus high incidence of Graves' disease in the young in a high iodine intake area: comparative surveys of throtoxicosis epidemiology in East-Jutland Denmark and Iceland. Journal of Internal Medicine 1991229 415-420.

13 Manji N, Carr-Smith JD, Boelaert K, Allahabadia A, Armitage M, Chatterjee VK, Lazarus JH, Pearce SH, Vaidya B, Gough SC \& Franklyn JA. Influence of age, gender, smoking, and family history on autoimmune thyroid disease phenotype. Journal of Clinical Endocrinology and Metabolism 2006 91 4873-4880.

14 Winsa B, Adami HO, Bergström R, Gamstedt A, Dahlberg PA, Adamson U, Jansson R \& Karlsson A. Stressful life events and Graves' disease. Lancet 1991338 1475-1479.

15 Rothman KJ, Greenland S \& Lash T. Modern Epidemiology. 3rd edn, New York: Lippincott Williams \& Wilkins, 2008. 
16 Vagenakis AG, Wang CA, Burger A, Maloof F, Braverman LE \& Ingbar SH. Iodide induced thyrotoxicosis in Boston. New England Journal of Medicine 1972287 523-526.

17 Yang F, Shan Z, Teng X, Li Y, Guan H, Chong W, Teng D, Yu X, Fan C, Dai H, Yu Y, Yang R, Li J, Chen Y, Zhao D, Mao J \& Teng W. Chronic iodine excess does not increase the incidence of hyperthyroidism: a prospective community-based epidemiological survey in China. European Journal of Endocrinology $2007 \mathbf{1 5 6}$ 403-408.

18 Laurberg P, Jorgensen T, Perrild H, Ovesen L, Knudsen N, Pedersen IB, Rasmussen LB, Carle A \& Vejbjerg P. The Danish investigation on iodine intake and thyroid disease, DanThyr: status and perspectives. European Journal of Endocrinology $2006 \mathbf{1 5 5}$ 219-228.

19 Hansen PS, Brix TH, Iachine I, Kyvik KO \& Hegedus L. The relative importance of genetic and environmental effects for the early stages of thyroid autoimmunity: a study of healthy Danish twins. European Journal of Endocrinology 2006154 29-38.

20 Davies TF. Really significant genes for autoimmune thyroid disease do not exist - so how can we predict diseases. Thyroid $2007 \mathbf{1 7}$ 1027-1029.

21 Kawoura FK, Akamizu T, Awata T, Ban Y, Chistiakov DA, Frydecka I, Ghaderi A, Gough SC, Hiromatsu Y, Ploski R, Wang PW, Bednarczuk T, Chistiakova EI, Chojm M, Heward JM, Hiratani H, Juo SH, Karabon L, Katayama S, Kurihara S, Liu RT, Miyake I, Omrani GH, Pawlak E, Taniyama M, Tozaki T \& Ioannidis JP. Cytotoxic T-lymphocyte associated antigen 4 gene polymorphisms and autoimmune thyroid disease: a meta-analysis. Journal of Clinical Endocrinology and Metabolism 2007923162 3170.

22 Hägg E \& Asplund K. Is endocrine ophthamopathy related to smoking? BMJ $1987295634-635$.

23 Weetman AP. Autoimmune thyroid disease: propagatio and progression. European Journal of Endocrinology 2003148 1-9.
24 Soldin OP, Soldin SJ, Ressom H \& Landy H. Tobacco smoke exposure associations with thyroid and steroid hormone changes in women of reproductive age. Abstract. Thyroid 200717 S-101.

25 Chen C, Wang X, Wang L, Yang F, Tang G, Xing H, Ryan L, Lasley B, Overstreet JW, Stanford JB \& Xu X. Effect of environmental tobacco smoke on levels of urinary hormone markers. Environmental Health Perspectives 2005113 412-417.

26 Vestergaard P, Rejnmark L, Weeke J, Hoeck HC, Nielsen HK, Rungby J, Laurberg P \& Mosekilde L. Smoking as a risk factor for Graves' disease, toxic nodular goitre and autoimmune hypothyroidism. Thyroid $20021269-75$.

27 Strieder TG, Prummel MF, Tijssen JG, Endert E \& Wiersinga WM. Risk factors for and prevalence of thyroid disorders in a crosssectional study among healthy female relatives of patients with autoimmune thyroid disease. Clinical Endocrinology $2003 \mathbf{5 9}$ 396-401.

28 Benhaim Rochester D \& Davies TF. Increased risk of Graves' disease after pregnancy. Thyroid 200515 1287-1290.

29 Kisiel B, Bednarczuk T, Kostrzewa G, Kosinska J, Miskiewicz P, Plazinska MT, Bar-Andziak E, Krolicki L, Krajewski P \& Ploski R. Polymorphism of the estrogen receptor beta gene (ESR2) is associated with susceptibility to Graves' disease. Clinical Endocrinology $200868429-434$.

30 Kuiper S, van Gestel AM, Swinkels HL, de Boo TM, da Silva JA \& van Riel PL. Influence of sex, age and menopausal state on the course of early rheumatoid arthritis. Journal of Rheumatology 2001 28 1809-1816.

31 Spector TD, Brennan P, Harris P, Studd JW \& Silman AJ. Does estrogen replacement therapy protect against rheumatoid arthritis? Journal of Rheumatology 199118 1473-1476.

Received 18 October 2008

Accepted 8 November 2008 